This manuscript is contextually identical with the following published paper:

Erős, T., Takács, P., Specziár, A., Schmera, D., Sály, P (2017) Effect of landscape context on fish metacommunity structuring in stream networks. Freshwater Biology, 62, (2) 215-222. DOI: 10.1111/fwb.12857

The original published PDF available in this website:

http://onlinelibrary.wiley.com/doi/10.1111/fwb.12857/abstract

\title{
Effect of landscape context on fish metacommunity structuring in stream networks
}

Tibor Erős ${ }^{1 *}$, Péter Takács $^{1}$, András Specziár ${ }^{1}$, Dénes Schmera ${ }^{1}$, Péter Sály $^{1}$

${ }^{1}$ Balaton Limnological Institute, MTA Centre for Ecological Research, Klebelsberg K. u. 3., H-8237 Tihany, Hungary

*Corresponding author: e-mail address: eros.tibor@okologia.mta.hu, Tel.: +36 87448 244, Fax.: +36 87448006

Running head: fish metacommunities in stream networks 


\section{Summary}

1. The metacommunity framework has shed light upon the significance of local and regional processes in shaping ecological communities. However, our knowledge is limited how landscape context (i.e. type and positioning of habitats) influences the structuring of metacommunities.

2. We examined the role of environmental selection (niche based species sorting), dispersal and drift (i.e. stochastic changes in species abundance) mechanisms on the structuring of fish metacommunities in riverscapes. We used a hierarchical design and examined metacommunity structuring 1) in individual running water habitat types, namely highland streams, lowland streams, highland rivers, and lowland rivers, 2) in landscape types, where patterns in highland and in lowland types were examined separately, and 3) at the level of the whole riverscape, where samples from all running water types were pooled. Elements of metacommunity structure (EMS) analysis, community-environmental relationships in redundancy analysis, and decay of community similarity with distance (distance decay) complemented with partial Mantel tests were used to reveal the mechanisms behind the observed patterns.

3. Both the EMS framework and community-environment relationships revealed the prevalent role of selection (niche based species sorting mechanisms) on fish metacommunity structuring, although stochastic variability also influenced the results. Metacommunity structures reflecting niche based mechanisms (Clementsian or Quasi-Clementsian) were observed at higher hierarchical levels (i.e. at the riverscape and the landscape type levels), while Quasi-Clementsian or random patterns were found within single running water types. 4. Distance decay relationships indicated that dispersal limitation did not clearly affect metacommunity structuring in any combination of running water types. Partial Mantel tests showed that some part of the variation in distance decay could be explained by the correlation between environmental variables and fish assemblage structure in some habitat types, which further suggests the importance of niche based mechanisms in metacommunity structuring. 5. Our study shows that different metacommunity structures can arise in a hierarchy of habitat types in riverscapes, and niche based species sorting mechanisms are more influential in their structuring than dispersal ones. Landscape classifications are useful for a better understanding of the structuring of metacommunities in both the freshwater and the terrestrial realm.

Key words: metacommunities; distance decay; dispersal limitation; environmental selection; habitat types 


\section{Introduction}

A major goal of community ecology is to understand the assembly of species in local communities from the regional species pool by exploring the role of different ecoevolutionary mechanisms (Vellend, 2010). Testing community assembly mechanisms has also become a major research avenue in metacommunity ecology, a branch of community ecology which has emerged to find generalities in how local and regional scale processes determine the coexistence of species within landscapes (Leibold et al., 2004). These mechanisms can be indirectly inferred from examining species distributions patterns in a metacommunity (Logue et al., 2011).

A variety of distributional patterns have been identified in nature which can be identified with the Elements of metacommunity structure (EMS) approach (Leibold \& Mikkelson, 2002; Presley et al., 2010) and which can aid a better understanding of metacommunity structuring (Fig. 1, see methods for more details). For example, while a random distribution of species, which does not differ from specified null models, can be an indicator of the prominent role of drift mechanisms (i.e. stochastic changes in species abundance, see e.g. Vellend, 2010; Vellend et al., 2014), the degree of species turnover along environmental gradients may inform on the strength and type of environmental selection (i.e. niche based species sorting) at a variety of scales (Presley et al., 2010) and/or on the role of speciation acting at large spatial scales (Presley \& Willig, 2010). Clementsian distributions arise when groups of species show similar responses to environmental gradients and therefore can be classified into well-defined, distinctive community types (Clements, 1916). Gleasonian distributions reflect individualistic responses that yield a continuum of gradually changing composition without clumping (Gleason, 1926). Evenly-spaced gradients can occur in systems with intense interspecific competition in which trade-offs in competitive ability result in spatial distributions with evenly dispersed populations (Tilman, 1982). Alternatively, intense competition may manifest as mutually exclusive spatial distributions, resulting in checkerboard patterns (Diamond, 1975). Metacommunities with nested structure are associated with predictable patterns of species loss in which species-poor communities are proper subsets of more speciose communities; the resulting pattern of species loss is based often on species-specific characteristics such as dispersal ability, habitat specialization and tolerance to abiotic conditions (Patterson \& Atmar, 1986; Ulrich, Almeida-Neto \& Gotelli, 2012). Previous pattern identification methods mostly tested for the existence of a single spatial distribution (e.g., nested or checkerboard patterns). The advantage of the EMS 
approach is that it tests for multiple distributions simultaneously by discriminating among the idealised structures and their Quasi-structures, where turnover is insignificant (see Fig. 1), in a single set of analyses (Leibold \& Mikkelson, 2002; Presley et al., 2010).

Although the EMS approach is useful to find idealised metacommunity structures, it does not (or just indirectly) inform on the role niche-based species sorting (environmental filtering) or dispersal play in metacommunity structuring (Meynard et al., 2013; Heino et al., 2015a). Therefore, additional analyses, such as direct ordination methods or the examination of the decrease in community similarity with increasing spatial distance between the sampled sites (i.e. distance decay of similarity; Nekola and White, 1999; Soininen, McDonald \& Hillebrand, 2007) are necessary to disentangle the role ecological mechanisms play in metacommunity structuring (Meynard et al., 2013; Canedo-Argüelles et al., 2015; Heino et al., 2015a). It is likely that the relative role of environmental and spatial (dispersal related) mechanisms will depend on several aspects of landscape context (e.g. spatial location, arrangement and type of habitats in the landscape; Gustafson 1998) even within a single organism group and spatial scale (Willig et al., 2011). However, so far few studies have examined comparatively the similarities and differences in the idealised structure of metacommunities and its driving mechanisms in different landscapes (see e.g. Göthe et al., 2013; Meynard et al., 2013; Heino et al., 2015a). Syntheses are lacking for virtually any animal group, although it is clear that metacommunity structuring should be examined in a variety of landscape types in a single study and using the same methodological framework to establish reliable generalizations.

Dendritic stream networks are unique habitats (Campbell Grant, Lowe \& Fagan 2007), where, beside the type of the habitat, spatial positioning can have also critical importance in metacommunity structuring (Altermatt, 2013; Tonkin et al., 2015). For example, studies on stream macroinvertebrates suggested the importance of species sorting mechanisms in the most upstream, isolated part of the network and the increased importance of dispersal in more downstream, central parts of the network (Brown \& Swan, 2010; Göthe et al., 2013). However, we are not aware of any study from other organism groups which would have jointly considered the type and spatial positioning of the habitat in the structuring of stream metacommunities. To address this dearth of information, we use a hierarchical approach for a more mechanistic understanding of the structuring of metacommunities in stream networks (hereafter riverscapes, which includes the entire connected habitats of streams, rivers, and their riparian zones sensu Fausch et al., 2002). Specifically, we use stream fish communities 
for study organisms and examine their metacommunity structuring in four running water habitat types (highland streams, lowland streams, highland rivers, lowland rivers) and in their landscape level hierarchical combinations (Fig. 2). Finally, we examine the role of major environmental gradients and the possible role of dispersal in fish metacommunitiy structuring in this riverscape.

First, we hypothesized strong turnover in species distributions with either individualistic (Gleasonian) or clumped (Clementsian) responses of species to the environmental gradient at the riverscape level (i.e. when all samples are pooled). In fact, different running water habitat types maintain different fish communities in riverscapes, suggesting the importance of species turnover among the habitat types (Angermeier $\&$ Winston, 1999; Erős, 2007). However, how turnover effects manifest in the responses of species to environmental heterogeneity (i.e. Gleasonian vs Clementsian structure) are unknown. These latter patterns may indicate the prominent role of niche-based species sorting (environmental selection) mechanisms along long environmental gradients (Presley et al., 2010; Welsh and Hodgson, 2011). Second, we hypothesized that the importance of environmental selection may weaken at lower hierarchical levels, due to the decrease in the length of the environmental gradient, which may lead to the emergence of Quasi-structures (Erős et al., 2014; Heino et al., 2015a,b). Third, we predicted random or Quasi metacommunity structures at the lowest hierarchical level when all riverscape elements (HLS: highland streams, LLS: lowland streams, HLR: highland rivers, LLR: lowland rivers) are analysed separately. We predicted that environmental gradients are to too short within habitat types to meaningfully influence metacommunity structuring. Consequently, we predicted the weakening structuring effect of niche based species sorting along the nested hierarchy of habitat types, which may be revealed by the EMS approach. Finally, we hypothesized that dispersal mechanisms may have equal importance in all habitat types for an actively dispersing group like fish, which may yield significant distance decay relationships (DDR) between spatial distance of the sampling sites and community similarity (Maloney \& Munguia, 2011). Significant DDRs can arise due to species specific differences in mobility, neutral stochasticity (drift), and natural dispersal barriers, all of which may influence between-site patterns in community composition in real landscapes (Thompson \& Townsend 2006; Maloney \& Munguia, 2011; Lowe \& McPeek 2014; Vellend et al., 2014). 


\section{Materials and methods}

Study sites

We selected altogether 51 sampling sites in the Danube River catchment in the Pannon ecoregion, Hungary (Fig. 3). For distinguishing among the habitat types we used the map and typological system of Hungarian running waters, which distinguishes different running water types based on catchment size, altitude and substrate characteristics (Ministry of Environment and Water 2004, see also Erős, 2007; Schmera \& Baur, 2011). The criteria and the resulting classes correspond to the typological system recommended by the Water Framework Directive of the European Union, and are also frequently used in bioassessment studies (e.g. Sandin \& Verdonshott, 2006). Sample numbers distributed relatively equally among the running water types $(\mathrm{HLS}=15, \mathrm{LLS}=12, \mathrm{HLR}=12, \mathrm{LLR}=12)$. Sites were selected using geoinformatic maps in relatively intact catchments in a manner that large artificial barriers (e.g. large reservoir dams) do not constrain dispersal of organisms within the stream network. Care was taken that within-type mean spatial distance does not differ among the types. Mean and standard deviation of the pairwise stream distances among the sites were $860.0 \pm 427.6$, $753.4 \pm 465.8,884.3 \pm 463.8,569.5 \pm 400.3 \mathrm{rkm}$ in HLS, LLS, HLR, LLR, respectively. We believe that such a distance is ideal for testing metacommunity patterns in stream fish, because it is large enough that the populations cannot be considered as patchy populations, while they have the chance to interact via dispersal at ecological time scales (i.e. $10^{0}-10^{2}$ years, several generations for most fish species, Matthews, 1998). The total spatial gradient along which we could test community similarity and stream distance relationships ranged between 5 and $1500 \mathrm{~km}$ (see Appendix I, II, III), which is well within the migration distance of all fish species in this ecoregion even at reasonably long ecological time scales (i.e. $10^{2}$ years). Stream sites $(n=27)$ were wadeable and had a mean width of $2.8 \pm 0.8 \mathrm{~m}$ and a mean depth of $34.5 \pm 19.1 \mathrm{~cm}$, and a catchment size $<1000 \mathrm{~km}^{2}$. Rivers $(\mathrm{n}=24)$ had a mean width of $29.7 \pm 32.2 \mathrm{~m}$ and a mean depth of $84.6 \pm 54.3 \mathrm{~cm}$, and a catchment size $>1000 \mathrm{~km}^{2}$. Highland and lowland habitats differed mainly in substrate composition, average current velocity (HL: $36.7 \pm 26.4 \mathrm{~cm} \mathrm{~s}^{-1}$, LL: $17.3 \pm 18.1 \mathrm{~cm} \mathrm{~s}^{-1}$ ) and the coverage of macrophytes irrespective of the running water type (Appendix IV). The dominant land use type in the lowland catchments is agricultural (mainly arable lands), while deciduous forest is the characteristic land cover type in highland areas, especially in the valleys of both streams and rivers. 
Fish sampling

Fish were collected during August of 2013 with two types of electrofishing methods which were fully consistent with generally used electrofishing protocols (see e.g. Oberdorff et al., 2001; Pont et al., 2006). For streams, a battery-powered electrofishing device was used (Hans-Grassl IG 200/2B device, PDC). The crew sampled a $150 \mathrm{~m}$ long reach, slowly walking upstream and with single-pass fishing of the whole stream width. For non-wadeable rivers, boat electrofishing was applied with a generator driven device (Hans-Grassl EL64 II GI device, max $7000 \mathrm{~W}$, DC), slowly moving downstream and electrofishing $500 \mathrm{~m}$ long reaches in near shore areas. This division in sampling length between streams and rivers was necessary to optimize sampling effort and to sample fish assemblages representatively and proportionally to the size of the water body. Species richness estimators showed that such an effort catches most fish species ( $>85 \%$ ) in a single occasion in both $\mathrm{S}$ and $\mathrm{R}$ types in this ecoregion (see Erős, 2007; Sály et al., 2009 for details). After identification and counting, fish were released into the water at the site of capture. Although we sampled fish in a single occasion, results of this and other studies (e.g. Wang et al., 2003; Erős, 2007; Esselman \& Allan, 2010) show that the applied sampling method provides robust estimation of fish community characteristics at such a spatial scale. Such a survey design (i.e. reach scale survey in a single occasion) is commonly used for studying metacommunities of stream organisms (see e.g. Magalhães et al., 2002; Brown \& Swan, 2010; Maloney \& Munguia, 2011; Grönroos et al., 2013; Heino et al., 2015a,b).

\section{Habitat characterization}

In streams, 6-15 transects (depending on the complexity of the habitat, Sály et al. 2011) were placed perpendicular to the main channel at each sampling site to characterize physical features of the environment (see Appendix V). Wetted width was measured along each transect. Water depth and current velocity (at 60\% depth) were measured at three to six(varied according to the width) equally spaced points along each transect. Visual estimates of percentage substratum cover were made at every transect point as well (see Appendix V for categories). Percentage substratum data of the transect points were later pooled and overall percentage of substrate categories were calculated for each site. No transect-based measurements could be conducted in rivers. Here, mean width was measured using the landscape images from Google Earth, while mean velocity and water depth were measured along the electrofished sampling reach at 10-15 points. Visual estimates of percentage substratum cover were made at every transect point as well using grab sampling if it was 
necessary. Macrovegetation (emergent, submerged, floating) and periphyton coverage was estimated visually for the total area of the sampled reach. Water temperature, conductivity, dissolved oxygen content, and $\mathrm{pH}$ were measured with an OAKTON Waterproof PCD 650 portable handheld meter before fish sampling, and the content of nitrogen forms (i.e., nitrite, nitrate, ammonium), calcium and phosphate were measured using field kits (Visocolor ECO, Macherey-Nagel GmbH \& Co. KG., Germany). Percentage coverage of vegetation at the stream margin (i.e. along a $10 \mathrm{~m}$ wide strip in both sides) was estimated visually distinguishing herbaceous and arboreal categories. Percentage coverage of undercut banks was also visually estimated. Altitude was measured in the field using a GPS device (Garmin Montana 650). We used these variables as these provide meaningful information on both catchment and instream level characteristics of the habitat including possible human effects (Wang et al., 2003; Hoeinghaus, Winemiller \& Birnbaum, 2007; Erős et al., 2012).

\section{Data analysis}

Elements of metacommunity structure

Following Leibold and Mikkelson (2002) and Presley et al. (2010), we analysed aspects of coherence, species turnover, and boundary clumping (elements of metacommunity structure [EMS] analysis) to characterize metacommunity structure (Fig. 1) in this riverscape. We used reciprocal averaging (also called correspondence analysis, CA), an unconstrained ordination method, to arrange the sampling sites so that sites with similar species composition are adjacent and to arrange the order of species so that species with similar spatial distributional range (i.e., spatial occurrence patterns) are closer together. One of the advantages of using this ordination technique is that one does not have to a priori specify which environmental variables to include because the first axis is based on maximum association between site scores and species scores (Leibold \& Mikkelson, 2002). That is, the primary axis represents the strongest relationship between species composition within a site and spatial distribution of species among sites. After rearranging the data matrix, we tested for coherence in species occurrences along the environmental gradient defined by the first ordination axis (CA1). We counted the number of embedded absences (gaps in species distributions) and compared that number to a null distribution created from a null model with 1000 iterations. The null model constrained simulated species richness of each site to equal empirical richness, with marginal probability occurrences for each species (Heino et al., 2015a). If the number of embedded absences was significantly different from random with more embedded absences than that expected by chance, we considered coherence to be 
negative. This suggests that trade-offs in competitive ability between species may manifest as a 'checkerboard' like spatial distribution (Diamond, 1975). If the number of embedded absences was significantly less than that expected by chance, we considered the coherence within the metacommunity to be positive. Positive coherence indicates that a majority of the species are responding similarly to a latent environmental gradient defined by the primary axis of variation (Leibold \& Mikkelson, 2002).

For metacommunities that were positively coherent, an additional aspect (species turnover) was considered. Species turnover was measured as the number of times one species replaced another between two sites (i.e., number of replacements) for each possible pair of species and for each possible pair of sites. A replacement between two species (e.g., species A and $\mathrm{B}$ ) occurs when the range of species $\mathrm{A}$ extends beyond that of species $\mathrm{B}$ at one end of the gradient and the range of $\mathrm{B}$ extends beyond that of $\mathrm{A}$ at the other end of the gradient. The observed number of replacements in a metacommunity is compared to a null distribution that randomly shifts entire ranges of species (Leibold \& Mikkelson, 2002). Significantly low (negative) turnover is consistent with nested distributions, and significantly high (positive) turnover is consistent with Gleasonian, Clementsian, or evenly spaced distributions, requiring further analysis of boundary clumping to distinguish among them. Boundary clumping quantifies the distribution of all species, determining whether the metacommunity is clumped, evenly-spaced, or random with respect to the spatial distribution of species across the region (Leibold \& Mikkelson, 2002). We quantified the degree of boundary clumping using Morisita's index, which is typically viewed as a statistical measure of dispersion of individuals in a population (Morisita, 1971). However, this index can be extrapolated to include the dispersion of species in a metacommunity (Leibold \& Mikkelson, 2002). Index values significantly greater than 1 indicated substantial boundary clumping (i.e., Clementsian distribution), values significantly less than 1 indicated evenly spaced boundaries, and values not significantly different from 1 indicated randomly distributed species boundaries (i.e., Gleasonian distribution). Finally, metacommunities with positive coherence and nonsignificant turnover have a non-random structure, which lead to the establishment of Quasistructures (Presley et al., 2010). Each idealized pattern (i.e. Clementsian, Gleasonian, evenly spaced, nested) has at least one (or more) Quasi-structure counterpart (see Fig. 1), which indicate the effects of weaker structuring mechanisms than in those idealized structures in which turnover is significant (Presley et al., 2010).

We performed the analyses in the hierarchy of habitat types (Fig. 2). That is we first characterized idealised metacommunity structure at the level of the whole riverscape, when all 
riverscape elements (i.e. both streams [S] and rivers [R] from highland [HL] and lowland [LL] landscapes) were pooled. We also examined metacommunity structures in highland and lowland landscape types (i.e. S and R nested within HL and LL landscape types). Then, we characterized metacommunity structures at the lowest hierarchical level when highland and lowland streams and rivers (HLS, LLS, HLR, LLR) were examined separately. Rare species (species representing $<0.1 \%$ relative abundance and/or species that occurred only at one site, altogether 8 species) were removed prior to analyses to reduce their disproportional effect on the results (Legendre and Legendre 1998). Altogether 34 species and 15746 individuals were used for the study in this and the subsequent analyses.

\section{Environmental effects}

We used redundancy analysis (RDA) (Legendre \& Legendre 1998) using adjusted- $R^{2}$ values (Peres-Neto et al. 2006) to quantify the relative contribution of environmental variables to community structuring at the riverscape level, which is essential to get inferences on the role of niche based species sorting mechanisms. By distinguishing the different habitat types on the RDA figure (see Fig 4a), we have examined how well the communities of the habitat types are separated along the most influential environmental gradients. Such a visualisation effectively complements the EMS approach. Although, it cannot reliably distinguish among all idealised structures (e.g. nestedness, checkerboard), it can help to visualize the variability of communities within and between habitat types along environmental gradients.

Consequently, it is useful to further reveal the importance of turnover and clumping in metacommunity structuring.

Prior to data analyses, among-variable correlations were calculated to reduce the explanatory variables to those not strongly correlated to each other $(\mathrm{r}<0.7)$. Strongly skewed variables with many zero values were also omitted from further analyses. The environmental variables were then transformed based on their scale of measurement to improve their normality and reduce heteroscedasticity (see Appendix IV). They were also screened via a forward selection procedure with Monte Carlo randomization tests (4999 runs) to obtain a reduced set of significant variables for the final model (variables retained at $P<0.05$ ). Fish abundance data were Hellinger transformed prior to the analyses.

Note, that we did not want to use variance partitioning to quantify the effect of spatial variables and hereby getting inferences on the effects of dispersal and/or drift (neutral stochasticity) mechanisms, since several studies (see Tuomisto \& Ruokolainen, 2008; Gilbert \& Benett, 2010; Smith \& Lundholm, 2010; Vellend et al., 2014 for details), and our own 
simulations, specifically developed for stream networks (Sály \& Erös, 2016), show that this method is not really reliably for this purpose. We believe that with the examination of DDRs (see below), we could more reliable quantify the importance of spatial distance on community composition and abundance and hereby getting some inferences on the role of dispersal limitation (Tuomisto \& Ruokolainen, 2008).

\section{Distance decay}

First, curvilinear distances (with a precision of $0.1 \mathrm{~km}$ ) among the sampling sites were measured along the stream network in a GIS based environment (QGIS Development Team 2014) to get the pairwise stream distance matrix of the sampling sites. Second, pairwise community similarities were quantified using the Jaccard and Bray-Curtis similarity indices (for the formulae see Legendre \& Legendre, 1998) for presence-absence and for Hellinger transformed abundance data, respectively. To compute pairwise environmental similarities for the sites we followed the methods of Brown and Swan (2010). First, a principal component analysis of the correlation matrix of the environmental variables was done. Principal components with an eigenvalue greater than one were retained, and pairwise Euclidean distances of the sites were computed from the site scores of the retained principal coordinates (Brown \& Swan, 2010). Finally, distances were transformed into similarities by subtracting them from one.

The strength of the statistical relationship between pairwise spatial distance and pairwise community and environmental similarities, respectively, was quantified by the coefficient of determination $\left(\mathrm{R}^{2}\right)$ of a linear regression model. Significance of the relationship (alpha $=$ 0.05) was tested using a Monte Carlo permutation procedure. This test was necessary, because pairwise similarity values are not independent from each other, hence standard error of the regression slope parameter estimated from raw data is biased in this case. Randomization procedures were conducted with an R code written by Pierre Legendre (available at: http://adn.biol.umontreal.ca/ numericalecology/Rcode/; accessed 1st April 2015). In these analyses, if a distance decay in both environmental similarity and community similarity was found, it would suggest the effect of environmental selection (abiotic effects) on metacommunity structuring along a spatial gradient, which can be manifested in a spatial autocorrelation between environmental and community similarities. On the other hand, a significant distance decay in community similarity, but insignificant distance decay in environmental similarity would suggest the effect of dispersal limitation in metacommunity structuring. Finally, we also applied partial Mantel tests to examine the relationship between 
environmental and community distance matrices by partialling out the influence of spatial distance among the sampling sites (Legendre \& Legendre, 1998; for a recent application see e.g. Harrington, Poff \& Kondratieff, 2016). A significant relationship may indicate the effect of environmental heterogeneity on community structuring. For the analyses we used the same data matrices as for the testing of DDRs.

All statistical analyses were performed in R (R Development Core team, 2011) using the packages metacom (Dallas, 2013), and vegan (Oksanen et al., 2010).

\section{Results}

The EMS analysis indicated four metacommunity patterns (Table 1). At the riverscape level results of the EMS analysis indicated positive coherence, turnover and clumping, which is indicative of a Clementsian pattern. Both highland (HL) and lowland (LL) landscape types displayed a Quasi-Clementsian metacommunity structure (positive coherence, non-significant turnover and positive clumping). Finally, Quasi-Clementsian (LLR, HLS) and random (LLS, HLR) distributions were found at the lowest hierarchical level.

The RDA analysis explained $32.6 \%$ of the variance, and indicated variation in fish communities among the different running water types along well definable environmental gradients, supporting the result of EMS analysis (Fig. 4a). The running water types separated well along the first two RDA axes indicating the existence of Clementsian metacommunity structure at the riverscape level. The first axis of the RDA explained $15.1 \%$ of the total variance and $46.2 \%$ of total explained variance. It was most influenced by altitude, the proportion of coarse gravel and the coverage of emergent plants, which corresponded with the separation of highland vs lowland communities. The second RDA axis explained $11.1 \%$ of the total variance and $34.0 \%$ of total explained variance. It was most influenced by wetted width and to a lesser extent $\mathrm{pH}$ and, therefore, it separated communities to stream and river types. At the lowest hierarchical level, communities changed along shorter environmental gradients, but showed relatively high variability. These patterns in the RDA ordination plane support the existence of random or Quasi-Clementsian structures at the lowest hierarchical level of running water types (i.e., HLS, HLR, LLS, LLR).

Fish species most strongly associated with the different running water types are shown in Fig. $4 \mathrm{~b}$. The most common species of highland streams included common, mainly small bodied sedentary species such as the nemacheilid Barbatula barbatula, and the cyprinid Phoxinus phoxinus, Gobio obtusirostris, and Squalius cephalus. Fish species most strongly associated with lowland streams included the cyprinid Scardinius erythrophthalmus, , Rhodeus sericeus, 
the cobitid Misgurnus fossilis and the non-native cyprinid Carassius gibelio. Highland rivers included larger bodied, medium distance migratory cyprinid species such as Barbus barbus, Chondrostoma nasus, Vimba vimba, and the Danubian endemic percid Zingel streber. Species most strongly associated with lowland rivers included the cyprinid Alburnus alburnus, Abramis brama, Blicca bjoerkna and the percid Sander lucioperca.

Distance decay relationships were significant in five of the seven running water type combinations using presence/absence (Jaccard) data (Table 2; Appendix I, II, III). For relative abundance (Bray-Curtis) data distance decay relationships were significant in two cases (Table 2; Appendix I, II, III). Overall, however, the strength of the relationship (i.e. the explained variance) was extremely low in most cases (significant $\mathrm{R}^{2}$ values varied between 0.012 and 0.045 , with the exception of HLR, where it was 0.168 ). Environmental similarity of the sampling sites showed significant DDRs in only two of the seven types (Table 3). However, similarly to community DDRs, rates of decay and the explained variance were extremely low in all cases. After partialling out the effect of spatial distance, Mantel tests showed significant relationships between environmental heterogeneity and community structure for both presence/absence (Jaccard) or relative abundance (Bray-Curtis) data at the whole riverscape level, in the case of the highland landscape type, and in the case of highland streams (Table 4).

\section{Discussion}

In this study we used a series of complementary statistical analyses to better understand the mechanism that influence fish metacommunity structuring in riverscapes. The elements of metacommunity structure analysis (EMS) provided an effective way to define the dominant (best fit) metacommunity structures in hierarchically organized habitat types. We identified Clementsian distribution (i.e. with significantly positive coherence, turnover and clumping) at the riverscape (i.e. stream network) level, which shows the importance of niche-based selection mechanisms along relatively long environmental gradients. At lower hierarchical levels, the dominant structure was Quasi-Clementsian, which still indicates a clear role, albeit weaker, of niche-based species sorting on metacommunity structuring along shorter environmental gradients (Presley et al., 2010; Erős et al., 2014). The results thus support our hypothesis that lower environmental heterogeneity does not induce strong species responses within individual habitat types (e.g. Quasi-Clementsian structures with non-significant turnover in HLS or random structure with non-significant coherence and turnover in HLR), which would have resulted in clear Clementsian or Gleasonian patterns. On the contrary, 
contrasting environmental differences between the habitat types led to relatively well separated communities at the whole riverscape level.

Since the introduction of the EMS framework (Leibold \& Mikkelson, 2002), ecologists have identified a variety of best-fit metacommunity structures in nature and highlighted the role of selection (i.e. environmental filtering, Hoverman et al., 2011; López-Gonzalez et al., 2012) and/or speciation (Presley \& Willig, 2010; Henriques-Silva et al, 2013) in shaping these patterns. For freshwater organisms (i.e. bacteria, algae, macrophytes, invertebrates and fish) Clementsian and Quasi-nested patterns were the most commonly found structures, beside random, Quasi-Clementsian, Gleasonian, and Quasi-Gleasonian, which were less common (Erős et al., 2014; Heino et al., 2015a, b; Tonkin et al., 2016). Our study on stream and riverine fish generally support these findings. It highlights the outmost importance of turnover, and interestingly clumping in the structuring of fish communities. It also shows that different best-fit structures can emerge in different habitat types for the same organism group (here fish), corroborating a study on stream macroinvertebrates, where Clementsian or QuasiClementsian distributions were characteristic for headwater, mid-sized and large river communities (Tonkin et al., 2015).

If the EMS method proves to be sensitive to sample size, it might pose limitations to our study since sample number differed among the hierarchical habitat types and it was relatively small at the lowest hierarchical level. In this case the weakening pattern across the different hierarchical scales (i.e. from Clementsian to Quasi-Clementsian to random or QuasiClementsian) could be a sampling artefact. We believe this is not the case in this study since our country level collections (e.g. Erős, 2007) prove that the randomly selected sites embraced the habitat gradient within each type even at the lowest hierarchical level (e.g. HLS, LLR). Nevertheless, it is possible that the EMS approach is just as sensitive to the spatial design of the study as to the method of variance partitioning of environmental and spatial fractions in the metacommunity context (see Sály \& Erős, 2016). Consequently, while empirical studies on the structure of metacommunities are accumulating rapidly, we suggest that simulation based studies explore the sensitivity of the EMS analysis to the properties of the sampling design.

The total variance explained by the environmental RDA analysis was comparable to or even higher than the values found in other biogeographic regions for stream organisms (e.g. Göthe et al., 2013; Grönroos et al., 2013; Henriques-Silva et al., 2013; Heino et al., 2015a, c). Niche based species sorting is therefore clearly the most prominent mechanism shaping metacommunity structuring in this system, similarly to the findings of other studies on stream 
organisms (see Heino et al., 2015c for a review). Samples separated relatively well along the RDA axes when grouped by habitat type (e.g. highland and lowland types along the first axis, rivers and streams along the second axis). These results generally support the results of EMS analysis on the significant clumping of fishes (Clementsian and Quasi-Clementsian structures) and show that this clumping is mainly governed by the response of fishes to environmental gradients between and within the habitat types. Distribution for the common fishes (see Fig 4b) were in agreement with what is known about their species distribution along altitudinal, width (streams vs rivers) and substrate gradients in Europe (Erös, 2007; Lasne et al., 2007; Penczak et al. 2012).

Beside niche based species sorting, dispersal mechanisms can also significantly influence metacommunity structuring in riverscapes (Heino et al., 2015c). However, results on DDRs suggest that neither dispersal (movement of organisms through the landscape) nor dispersalrelated drift (i.e. neutral or mass effect mechanisms) influenced metacommunity structuring in this system in a biologically meaningful manner. In fact, partial Mantel tests showed that some part of the variation in distance decay could be explained by the correlation between the environmental variables and fish assemblage structure in some habitat types, which further highlights the importance of niche based mechanisms in metacommunity structuring. It is likely that the examination of longer spatial gradients should have resulted stronger DDRs, and we must emphasize that our study was restricted to a single ecoregion and to a spatial scale of 5-1500 km (see Appendix I, II, III). At larger spatial extents (e.g. between ecoregions) the role of speciation mechanisms may have prevalence over the effect of "local" species pools (Maloney \& Munguia, 2011; Heino \& Alahuhta, 2015). In light of the biologically rather insignificant spatial effects, it is also likely that most of the unexplained component indicated by the RDA model is related to unmeasured variables and/or to local (site level) drift (stochastic variability), such as for example temporal differences in the abiotic conditions between sites, which influenced site level community composition and abundance differentially. However, it is hard to disentangle the real reasons of either dispersal or site level drift mechanisms based on large scale field studies (Vellend et al., 2014) and without systematically-repeated field observations (Erős et al., 2012).

In conclusion, this study shows that studying metacommunity structuring in a hierarchy of habitat types can be fruitful for a better understanding of riverscape level patterns and mechanisms. Our study about stream and riverine fish communities contribute to the growing evidence that niche based species sorting has paramount importance over dispersal mechanisms (dispersal limitation, mass or neutral effects) in the structuring of 
metacommunities in riverscapes. To this end, we emphasize the importance of landscape context for a more mechanistic understanding of metacommunites in any animal group. Since landscape classifications are widely used in both freshwater (e.g. Poole, 2002; Higgins et al., 2004) and terrestrial (Turner, Gardner \& O’Neill, 2001; Lemessa, Hambäck \& Hylander, 2015) systems, we believe that a hierarchical examination of habitat types can contribute considerably to a better understanding of the role of landscape context to metacommunity structuring.

\section{Acknowledgments}

This work was supported by the OTKA K104279 grant and the Bolyai János Research Scholarship of the Hungarian Academy of Sciences (TE). We would like to express our thanks for Jani Heino for pre-reviewing the ms, and for numerous people for their help in the field work, but Gabriella Bodnár, and Endre Bajka, especially. Comments by two anonymous referees contributed largely to changes and improvements in the ms.

\section{References}

Altermatt F. (2013) Diversity in riverine metacommunities: a network perspective. Aquatic Ecology, 47, 365-377.

Angermeier, P. L. \& Winston, M. R. (1999) Characterizing fish community diversity across Virginia landscapes: prerequisite for conservation. Ecological Applications 9, 335-349.

Brown B.L. \& Swan C.M. (2010) Dendritic network structure constrains metacommunity properties in riverine ecosystems. Journal of Animal Ecology, 79, 571-580.

Campbell Grant, E.H., Lowe, W.H. \& Fagan, W.F. (2007) Living in the branches: population dynamics and ecological processes in dendritic networks. Ecology Letters, 10, 165 175.

Canedo-Argüelles M., Boersma K.S., Bogan M.T., Olden J.D., Philipsen I., Schriever T.A. \& Lytle D.A. (2015) Dispersal strength determines meta-community structure in a dendritic riverine network. Journal of Biogeography, 42, 778-790.

Clements F.E. (1916) Plant succession: An analysis of the development of vegetation. Carnegie Institute of Washington, Washington, DC.

Dallas T. (2013) metacom: Analysis of the 'elements of metacommunity structure'. R package version 1.3. http://CRAN.R-project.org/package $=$ metacom

Diamond J.M. (1975) Assembly of species communities. In Cody, M.L. and Diamond, J.M. (eds). Ecology and evolution of communities. Harvard University Press. 
Erős T., Sály P., Takács P., Higgins C.M., Schmera D. \& Bíró P. (2014) Quantifying temporal variability in the metacommunity structure of stream fishes: the influence of non-native species and environmental drivers. Hydrobiologia, 722, 31-43.

Erős T. (2007) Partitioning the diversity of riverine fish: the roles of habitat types and nonnative species. Freshwater Biology, 52, 1400-1415.

Erős T., Sály P., Takács P., Specziár A., Bíró P. (2012) Temporal variability in the spatial and environmental determinants of functional metacommunity organization - Stream fish in a human modified landscape. Freshwater Biology, 57, 1914-1928.

Erős T. \& Campbell Grant E.H. (2015) Unifying research on the fragmentation of terrestrial and aquatic habitats: patches, connectivity and the matrix in riverscapes. Freshwater Biology, 60, 1487-1501.

Esselman P.C. \& Allan J.D. (2010) Relative influences of catchment- and site-scale abiotic factors on freshwater fish communities in rivers of northeastern Mesoamerica. Ecology of Freshwater Fish, 19, 439-454.

Fagan W.F. (2002) Connectivity, fragmentation, and extinction risk in dendritic metapopulations. Ecology, 83, 3243-3249.

Fausch K.D., Torgersen C.E., Baxter C.V. \& Li H.W. (2002) Landscapes to riverscapes:

Bridging the gap between research and conservation of stream fishes. Bioscience, 52, 483-498.

Gilbert, B. \& Bennett, J.R. (2010) Partitioning variation in ecological communities. Do the numbers add up? Journal of Applied Ecology, 47, 1071-1082.

Gleason H.A. (1926) The individualistic concept of the plant association. Bulletin of the Torrey Botanical Club, 53, 7-26.

Göthe E., Angeler D.G. \& Sandin L. (2013) Metacommunity structure in a small boreal stream network. Journal of Animal Ecology, 82, 449-458.

Grönroos M., Heino J., Siqueira T., Landeiro V.L., Kotanen J. \& Bini L.M. (2013) Metacommunity structuring in stream networks: roles of dispersal mode, distance type, and regional environmental context. Ecology and Evolution, 3, 4473-4487.

Gustafson E.J. (1998) Quantifying landscape spatial pattern: what is the state of the art? Ecosystems, 1, 143-156.

Harrington R.A, Poff N.L.R. \& Kondratieff B.C. (2016) Aquatic insect b-diversity is not dependent on elevation in Southern Rocky Mountain streams. Freshwater Biology, 61, 195-205. 
Heino J. \& Alahuhta J. (2015) Elements of regional beetle faunas: faunal variation and compositional breakpoints along climate, land cover and geographical gradients. Journal of Animal Ecology, 84, 427-441.

Heino J., Nokela T., Soininen J., Tolkinnen M., Virtanen L. \& Virtanen R. (2015a) Elements of metacommunity structure and community-environment relationships in stream organisms. Freshwater Biology, 60, 973-988.

Heino J., Soininen J., Alahuhta J., Lappalainen J. \& Virtanen N. (2015b) A comparative analysis of metacommunity types in the freshwater realm. Ecology and Evolution, 5, $1525-1537$.

Heino J., Melo A., Siqueira T., Soininen J., Valanko S. \& Bini L.M. (2015c) Metacommunity organization, spatial extent and dispersal in aquatic systems: patterns, processes and prospects. Freshwater Biology, 60, 845-869.

Heino J., Melo A.S., Bini L.M., Altermatt F., Al-Shami S.A., Angeler D., Bonada N., Brand C., Callisto M., Cottenie K., Dangles O., Dudgeon D., Encalada A., Göthe E., Grönroos M., Hamada, N., Jacobsen D., Landeiro V.L., Ligeiro R., Martins R.T., Miserendino M.L., Md Rawi C.S., Rodrigues M., Roque F.O., Sandin L., Schmera D., Sgarbi L.F., Simaika J., Siqueira T., Thompson R.M. \& Townsend C.R. (2015d) A comparative analysis reveals weak relationships between ecological factors and beta diversity of stream insect metacommunities at two spatial levels. Ecology and Evolution, 5, 1235 1248 .

Henriques-Silva R., Lindo Z. \& Peres-Neto P.R. (2013) A community of metacommunities: exploring patterns in species distributions across large geographical areas. Ecology, 94, 627-639.

Higgins J.A., Bryer M.T., Khoury M.L. \& Fitzhugh T.W. (2004) A freshwater classification approach for biodiversity conservation planning. Conservation Biology, 19, 432-445.

Hoeinghaus D.J., Winemiller K.O. \& Birnbaum J.S. (2007) Local and regional determinants of stream fish assemblage structure: inferences based on taxonomic vs. functional groups. Journal of Biogeography, 34, 324-338.

Holyoak M., Leibold M.A. \& Holt R.D. eds 2005. Metacommunities: Spatial Dynamics and Ecological Communities. University of Chicago Press, 513pp.

Hoverman J.T., Davis C.J., Werner E.E., Skelly D.K., Relyea R.A. \& Yurewicz K.L. (2011) Environmental gradients and the structure of freshwater snail communities. Ecography, 34, 1049-1058. 
Hynes H.B.N. (1970) The ecology of running waters. University of Toronto Press, Toronto, Ontario, Canada

Lasne E., Bergerot B., Lek S. \& Laffaile P. (2007) Fish zonation and indicator species for the evaluation of the ecological status of rivers: example of the Loire basin (France). River Research and Applications, 23, 1-14.

Legendre P. \& Legendre L. (1998) Numerical Ecology. Elsevier, Amsterdam, The Netherlands, pp. $\mathrm{xv}+853$.

Leibold M.A., Holyoak M., Mouquet N., Amarasekare P., Chase J.M., Hoopes M.F., Holt R.D., Shurin J.B., Law R., Tilman D., Loreau M. \& Gonzalez A. (2004) The metacommunity concept: a framework for multi-scale community ecology. Ecology Letters, 7, 601-613.

Leibold M.A. \& Mikkelson, G.M. (2002) Coherence, species turnover and boundary clumping: elements of a metacommunity structure. Oikos, 97, 237-250.

Lemessa D., Hambäck P.A. \& Hylander K. (2015) The effect of local and landscape level land-use composition on predatory arthropods in a tropical agricultural landscape. Landscape Ecology, 30, 167-180.

Logue J.B., Mouquet N., Peter H., Hillebrand H., Declerck P., Flohre A., Gantner S., Gülzow N., Hörtnagl P., Meier S. \& Pecceu B. (2011) Empirical approaches to metacommunities: a review and comparison with theory. Trends in Ecology and Evolution, 26, 482-491.

López-González C., Presley S.J., Lozano A., Stevens R.D. \& Higgins C.L. (2012) Metacommunity analysis of Mexican bats: environmentally mediated structure in an area of high geographic and environmental complexity. Journal of Biogeography, 39, 177-192.

Lowe W.H. \& McPeek M.A. (2014) Is dispersal neutral? Trends in Ecology and Evolution, 29, 444-450.

Magalhães M.F., Batalha D.C. \& Collares-Pereira M.J. (2002) Gradients in stream fish assemblages across a Mediterranean landscape: contributions of environmental factors and spatial structure. Freshwater Biology, 47, 1015-1031.

Maloney K.O. \& Munguia P. (2011) Distance decay of similarity in temperate aquatic communities: effects of environmental transition zones, distance measures and life histories. Ecography, 34, 287-295.

Matthews W.J. (1998) Patterns in freshwater fish ecology. Chapman \& Hall, New York 
Meynard C.N., Lavergne S., Boulangeat I., Garraud L., Van Es J., Mouquet N. \& Thuiller W. (2013) Disentangling the drivers of metacommunity structure across spatial scales. Journal of Biogeography, 40, 1560-1571.

Ministry of Environment and Water (2004) Departmental Order 31/2004 (XII. 30.) on the

Rules of Assessment and Evaluation of Surface Waters in Hungary.

Morisita M. (1971) Composition of the I-index. Researches on Population Ecology, 13, 1-27.

Nekola JC. \& White P.S. (1999) The distance decay of similarity in biogeography and ecology. Journal of Biogeography, 26, 867-878.

Oberdorff T., Pont D., Hugueny B. \& Chessel D. (2001) A probabilistic model characterizing fish assemblages of French rivers: a framework for environmental assessment. Freshwater Biology, 46, 399-415.

Oksanen J., Blanchet F.G., Friendly M., Kindt R., Legendre P., McGlinn D., Minchin P.R., O’Hara R.B., et al. (2016) vegan: Community Ecology Package. R package version 2.4-1. Available online 07 September 2014 at: https://cran.rproject.org/web/packages/vegan/index.html

Patterson B.D. \& Atmar W. (1986) Nested subsets and the structure of insular mammalian faunas and archipelagos. Biological Journal of the Linnean Society, 28, 65-82.

Penczak T., Glowacki L., Kruk A. \& Galicka W. (2012) implementation of a self-organizing map for investigation of impoundment impact on fish assemblages in a large lowland river: Long-term study. Ecological Modelling, 227, 64-71.

Peres-Neto P.R., Legendre P., Dray S. \& Borcard D. (2006) Variation partitioning of species data matrices: estimation and comparison of fractions. Ecology, 87, 2614-2625.

Perkin J.S. \& Gido K.B. (2012) Fragmentation alters stream fish community structure in dendritic ecological networks. Ecological Applications, 22, 2176-87.

Poff N.L. (1997) Landscape filters and species traits: towards mechanistic understanding and prediction in stream ecology. Journal of the North American Benthological Society, 16, 391-409

Pont D., Hugueny B., Beier U., Goffaux D., Melcher A., Noble R., Rogers C., Roset N. \& Schmutz S. (2006) Assessing river biotic condition at a continental scale: a European approach using functional metrics and fish assemblages. Journal of Applied Ecology, 43, 70-80.

Poole G.C. (2002) Fluvial landscape ecology: addressing uniqueness within the river discontinuum. Freshwater Biology, 47, 641-660. 
Presley S.J. \& Willig M.R. (2010) Bat metacommunity structure on Caribbean islands and the role of endemics. Global Ecology and Biogeography, 19, 185-199.

Presley S.J., Higgins C.L. \& Willig M.R. (2010) A comprehensive framework for the evaluation of metacommunity structure. Oikos, 119, 908-917.

QGIS Development Team 2014. QGIS Geographic Information System. - Open Source Geospatial Foundation.

R Development Core Team (2010) R: A language and environment for statistical computing. R Foundation for Statistical Computing, Vienna, Austria. ISBN 3-900051-07-0, URL http://www.R-project.org.

Sály P., Erős T., Takács P., Specziár A., Kiss I. \& Bíró P. (2009) Assemblage level monitoring of stream fishes: The relative efficiency of single-pass vs. double-pass electrofishing. Fisheries Research, 99, 226-233.

Sály P., Takács P., Kiss I., Bíró P. \& Erős T. (2011) The relative influence of spatial context and catchment and site scale environmental factors on stream fish assemblages in a human-modified landscape. Ecology of Freshwater Fish, 20, 251-262.

Sály P. \& Erős T. (2016) Effect of field sampling design on variation partitioning in a dendritic stream network. Ecological Complexity, in press (http://dx.doi.org/10.1016/j.ecocom.2016.05.002)

Schmera D. \& Baur B. (2011) Testing a typology system of running waters for conservation planning in Hungary. Hydrobiologia, 665, 183-194.

Sandin L. \& Verdonschot P.F.M. (2006) Stream and river typologies-major results and conclusions from the STAR project. Hydrobiologia, 566, 33-37.

Schlosser I.J. (1991) Stream fish ecology - a landscape perspective. Bioscience, 41, 704-712.

Smith T.W. \& Lundholm J.T. (2010) Variation partitioning as a tool to distinguish between niche and neutral processes. Ecography, 33, 648-655.

Soininen J., McDonald R. \& Hillebrand H. (2007) The distance decay of similarity in ecological communities. Ecography, 30, 3-12.

Thompson R.M. \& Townsend C.R. (2006) A truce with neutral theory: local deterministic factors, species traits and dispersal limitation together determine patterns of diversity in stream invertebrates. Journal of Animal Ecology, 75, 476-484.

Tilman D. (1982) Resource Competition and Community Structure. Princeton University Press, Princeton 
Tonkin J.D., Sundermann A., Jähnig S.C. \& Haase P. (2015) Environmental controls on river assemblages at the regional scale: an application of the elements of metacommunity structure framework. PLoS One10(8): e0135450.

Tonkin J.D., Stoll S., Jähnig S.C. \& Haase P. (2016) Elements of metacommunity structure of river and riparian assemblages: Communities, taxonomic groups and deconstructed trait groups. Ecological Complexity, 25, 35-43.

Townsend C.R. (1989) The patch dynamics concept of stream community ecology. Journal of the North American Benthological Society, 8, 36-50.

Tuomisto H. \& Ruokolainen K. (2008) Analysing or explaining beta diversity? Reply. Ecology, 89, 3244-3256.

Turner M.G., Gardner R.H. \& O’Neill R.V. (2001) Landscape ecology in theory and practice: pattern and process. Springer-Verlag, New York 577.

Ulrich W., Almeida-Neto M. \& Gotelli N.J. (2012) A consumer's guide to nestedness analysis. Oikos, 118, 3-17.

Vellend M., (2010) Conceptual synthesis in community ecology. Quarterly Review of Biology, 85, 183-206.

Vellend M., Srivastava D.S., Anderson K.M., Brown C.D., Jankowski J.E., Kleynhans E.J., Kraft N.J., Letaw A.D., Macdonald A.A.M., Maclean J.E., Myers-Smith I.H., Norris A.R. \& Xue X. (2014) Assessing the relative importance of neutral stochasticity in ecological communities. Oikos, 123, 1420-1430.

Wang L., Lyons J., Rasmussen P., Seelbach P., Simon T., Wiley M., Kanehl P., Baker E., Niemela S. \& Stewart P.M. (2003) Watershed, reach, and riparian influences on stream fish assemblages in the Northern Lakes and Forest Ecoregion, U.S.A. Canadian Journal of Fisheries and Aquatic Sciences, 60, 491-505.

Willig M.R., Presley S.J., Bloch C.P., Castro-Arellano I., Cisneros L.M., Higgins C.L. \& Klingbeil B.T. (2011) Tropical metacommunities along elevational gradients: effects of forest type and other environmental factors. Oikos, 120, 1497-1508.

Welsh H.H. \& Hodgson G.R. (2011) Spatial relationships in a dendritic network: the herpetofaunal metacommunity of the Mattole River catchment of northwest California. Ecography, 34, 49-66. 
Table 1. Results of the EMS analysis for all stream types. HL, highland; LL, lowland; S, stream; R, river. Abs: the number of embedded absences in the ordinated (First axis of a correspondence analysis) matrix. Re: Species replacements. M: Morisita's index. NS: Nonsignificant. Mean and standard deviation (SD) values show the values calculated based on 1000 iterations of a null matrix (see Fig 1. and Methods for more details.)

\begin{tabular}{|c|c|c|c|c|c|c|c|c|c|c|c|c|c|c|}
\hline & $\begin{array}{l}\text { Coherence } \\
\text { Abs }\end{array}$ & $\mathrm{P}$ & Mean & SD & $\begin{array}{l}\text { Species turnover } \\
\text { Re }\end{array}$ & $\mathrm{P}$ & Mean & SD & $\begin{array}{l}\text { Boundary clumping } \\
\text { M }\end{array}$ & $\mathrm{P}$ & Coherence & Turnover & Clumping & Best-fit structure \\
\hline All sites & 593 & $<0.001$ & 864.097 & 33.663 & 23830 & $<0.001$ & 9402.465 & 3219.895 & 2.722 & $<0.001$ & Positive & Positive & Positive & Clementsian \\
\hline $\mathrm{HL}$ & 223 & $<0.001$ & 357.540 & 24.738 & 4841 & 0.840 & 4532.232 & 1533.393 & 3.969 & $<0.001$ & Positive & NS+ & Positive & Quasi-Clementsian \\
\hline LL & 203 & $<0.001$ & 290.900 & 20.209 & 2611 & 0.740 & 2939.217 & 989.049 & 2.409 & $<0.001$ & Positive & NS+ & Positive & Quasi-Clementsian \\
\hline HLS & 48 & $<0.001$ & 122.719 & 12.697 & 1006 & 0.374 & 1408.34 & 455.698 & 3.826 & $<0.001$ & Positive & NS+ & Positive & Quasi-Clementsian \\
\hline HLR & 74 & 0.249 & 84.188 & 8.835 & 860 & 0.170 & 617.969 & 176.481 & 1.515 & 0.071 & NS & NS+ & Positive & Random \\
\hline LLS & 85 & 0.173 & 98.557 & 9.955 & 795 & 0.553 & 972.833 & 299.867 & 1.766 & 0.019 & NS & NS+ & Positive & Random \\
\hline LLR & 76 & 0.018 & 98.076 & 9.369 & 776 & 0.878 & 742.201 & 220.581 & 2.736 & $<0.001$ & Positive & NS+ & Positive & Quasi-Clementsian \\
\hline
\end{tabular}


Table 2. Summary statistics of distance decay relationships (regression coefficients [slope, b], adjusted $\mathrm{R}^{2}$ and $\mathrm{P}$ values) in fish communities in a hierarchy of running water types using Jaccard and Bray-Curtis coefficients. HL, highland; LL, lowland; S, stream; R, river.

\begin{tabular}{ccccccc}
\hline & \multicolumn{3}{c}{ Jaccard } & & \multicolumn{3}{c}{ Bray-Curtis } \\
& $\mathrm{b}$ & $\mathrm{adj} \mathrm{R}^{2}$ & $\mathrm{P}$ & $\mathrm{b}$ & adj R $^{2}$ & $\mathrm{P}$ \\
\hline all sites & $<-0.001$ & 0.016 & $<0.001$ & $<-0.001$ & 0.011 & $<0.0001$ \\
HL & $<-0.001$ & 0.016 & 0.005 & $<-0.001$ & 0.003 & 0.158 \\
LL & $<-0.001$ & 0.012 & 0.046 & $<-0.001$ & 0.001 & 0.379 \\
HLS & $<-0.001$ & 0.045 & 0.020 & $<-0.001$ & 0.042 & 0.022 \\
HLR & $<-0.001$ & 0.168 & $<0.001$ & $<-0.001$ & 0.002 & 0.307 \\
LLS & $<-0.001$ & 0.007 & 0.241 & $<-0.001$ & 0.014 & 0.167 \\
LLR & $<-0.001$ & 0.009 & 0.205 & $<-0.001$ & 0.010 & 0.207 \\
\hline
\end{tabular}


Table 3. Summary statistics of distance decay relationships (regression coefficients [slope, b], adjusted $\mathrm{R}^{2}$ and $\mathrm{P}$ values) in environmental similarity among the sampling sites in a hierarchy of running water types. HL, highland; LL, lowland; S, stream; R, river.

\begin{tabular}{cccc}
\hline & \multicolumn{3}{c}{ Environmental similarity } \\
& $\mathrm{b}$ & $\mathrm{adj} \mathrm{R} \mathrm{R}^{2}$ & $\mathrm{P}$ \\
\hline all sites & $<-0.001$ & 0.003 & 0.032 \\
HL & $<-0.001$ & 0.001 & 0.508 \\
LL & $<-0.001$ & 0.015 & 0.025 \\
HLS & $<-0.001$ & 0.009 & 0.160 \\
HLR & $<-0.001$ & 0.016 & 0.951 \\
LLS & $<-0.001$ & 0.014 & 0.770 \\
LLR & $<-0.001$ & 0.017 & 0.147 \\
\hline
\end{tabular}


Table 4. Summary statistics of partial Mantel tests ( $\mathrm{r}$ and $\mathrm{P}$ values). Significant relationships indicate correlation between pure environmental distance and community distance matrices (using Jaccard and Bray-Curtis coefficients) in a hierarchy of running water types. HL, highland; LL, lowland; S, stream; R, river.

\begin{tabular}{ccccc}
\hline & \multicolumn{2}{c}{ Jaccard } & \multicolumn{2}{c}{ Bray-Curtis } \\
& rM & P & rM & P \\
\hline all sites & 0.317 & $<0.001$ & 0.352 & $<0.001$ \\
HL & 0.331 & $<0.001$ & 0.306 & $<0.001$ \\
LL & 0.134 & 0.123 & 0.158 & 0.086 \\
HLS & 0.355 & 0.004 & 0.269 & 0.016 \\
HLR & -0.070 & 0.640 & 0.101 & 0.326 \\
LLS & -0.019 & 0.549 & -0.100 & 0.694 \\
LLR & 0.114 & 0.255 & 0.128 & 0.233 \\
\hline
\end{tabular}


Appendix IV. Environmental characteristics of the four running water types. HL, highland; LL, lowland; S, stream; R, river.

\begin{tabular}{|c|c|c|c|c|c|c|c|c|c|c|c|c|c|}
\hline & \multirow[b]{2}{*}{ Transformation } & \multicolumn{3}{|c|}{ HLS } & \multicolumn{3}{|c|}{ HLR } & \multicolumn{3}{|c|}{ LLS } & \multicolumn{3}{|c|}{ LLR } \\
\hline & & Median & Min & Max & Median & Min & Max & Median & Min & Max & Median & Min & Max \\
\hline Altitude (m a.s.l.) & $x^{\prime}=\ln (x+1)$ & 203 & 113 & 261 & 146.5 & 109 & 227 & 108 & 95 & 180 & 103 & 85 & 119 \\
\hline$\%$ Undercut bank & - & 0 & 0 & 80 & 0 & 0 & 5 & 0 & 0 & 0 & 0 & 0 & 30 \\
\hline$\%$ Herbaceous bank vegetation & - & 50 & 0 & 100 & 50 & 0 & 100 & 100 & 50 & 100 & 37.5 & 0 & 65 \\
\hline$\%$ Arboreal bank vegetation & $x^{\prime}=\arcsin \left(x^{0.5}\right)$ & 50 & 0 & 100 & 50 & 0 & 100 & 0 & 0 & 50 & 62.5 & 35 & 100 \\
\hline Wet width (m) & $x^{\prime}=\ln (x+1)$ & 2.9 & 1.6 & 4.3 & 18 & 5.8 & 155 & 2.85 & 1.6 & 4.2 & 20 & 5 & 47 \\
\hline Depth $(\mathrm{cm})$ & - & 28 & 15 & 78.7 & 60 & 40 & 90 & 33 & 15 & 80 & 107.5 & 1.5 & 250 \\
\hline Current velocity $\left(\mathrm{cm} \mathrm{s}^{-1}\right)$ & $x^{\prime}=\ln (x+1)$ & 18 & 4.55 & 31 & 60 & 18 & 90 & 8 & 2 & 25 & 20 & 3 & 65 \\
\hline$\%$ Marl or silt (diameter $0-0.02 \mathrm{~mm}$ ) & - & 0 & 0 & 20 & 0 & 0 & 0 & 0 & 0 & 0 & 10 & 0 & 100 \\
\hline $\begin{array}{l}\text { \% Silty sand (diameter } 0.02-0.2 \\
\mathrm{~mm} \text { ) }\end{array}$ & $x^{\prime}=\arcsin \left(x^{0.5}\right)$ & 20 & 0 & 87.5 & 12.5 & 0 & 30 & 100 & 20 & 100 & 35 & 0 & 100 \\
\hline$\%$ Sand (diameter $0.2-2 \mathrm{~mm}$ ) & $x^{\prime}=\arcsin \left(x^{0.5}\right)$ & 20 & 0 & 25 & 20 & 0 & 30 & 0 & 0 & 30 & 0 & 0 & 60 \\
\hline$\%$ Fine gravel (diameter 2-20 mm) & $x^{\prime}=\arcsin \left(x^{0.5}\right)$ & 20 & 0 & 55 & 27.5 & 5 & 60 & 0 & 0 & 60 & 0 & 0 & 40 \\
\hline $\begin{array}{l}\% \text { Coarse gravel (diameter 20-60 } \\
\mathrm{mm} \text { ) }\end{array}$ & $x^{\prime}=\arcsin \left(x^{0.5}\right)$ & 30 & 0 & 68.7 & 27.5 & 10 & 80 & 0 & 0 & 10 & 0 & 0 & 30 \\
\hline$\%$ Stone (diameter $60-300 \mathrm{~mm}$ ) & - & 0 & 0 & 30 & 0 & 0 & 20 & 0 & 0 & 0 & 0 & 0 & 5 \\
\hline$\%$ Rock (diameter >300 mm) & - & 0 & 0 & 20 & 0 & 0 & 40 & 0 & 0 & 10 & 0 & 0 & 1 \\
\hline$\%$ Emergent plant & $x^{\prime}=\arcsin \left(x^{0.5}\right)$ & 0 & 0 & 60 & 0 & 0 & 20 & 20 & 6 & 98 & 4.5 & 0 & 17 \\
\hline$\%$ Submerged plant & $x^{\prime}=\arcsin \left(x^{0.5}\right)$ & 0 & 0 & 13.7 & 0 & 0 & 6 & 6 & 0 & 30 & 4 & 0 & 20 \\
\hline$\%$ Floating leaved plant & $x^{\prime}=\arcsin \left(x^{0.5}\right)$ & 0 & 0 & 1.2 & 0 & 0 & 50 & 0 & 0 & 25 & 1 & 0 & 15 \\
\hline$\%$ Filamentous algae & - & 0 & 0 & 15 & 0 & 0 & 1 & 0 & 0 & 40 & 0 & 0 & 3 \\
\hline Temperature ( C) & - & 18.5 & 17.4 & 24.5 & 23.2 & 16.9 & 28.2 & 23.7 & 17.7 & 28.3 & 22.8 & 20 & 30.9 \\
\hline $\mathrm{pH}$ & not applied & 8.41 & 7.62 & 8.86 & 8.57 & 8.29 & 8.7 & 8.05 & 7.64 & 9.07 & 8.37 & 8.21 & 8.77 \\
\hline Dissolved oxygen $\left(\mathrm{mg} \mathrm{l}^{-1}\right)$ & - & 7.54 & 4.57 & 9.85 & 8.10 & 7.57 & 8.87 & 3.415 & 2.06 & 10.21 & 7.38 & 3.78 & 8.86 \\
\hline Conductivity $\left(\mu \mathrm{S} \mathrm{cm}^{-1}\right)$ & $x^{\prime}=\ln (x+1)$ & 690 & 142.4 & 1360 & 501.5 & 310 & 782 & 634 & 386 & 1432 & 614 & 324 & 1363 \\
\hline Nitrite $\left(\mu \mathrm{g}^{-1}\right)$ & $x^{\prime}=\ln (x+1)$ & 49 & 9 & 170 & 60.5 & 36 & 91 & 53.5 & 30 & 270 & 53 & 26 & 149 \\
\hline Nitrate $\left(\mathrm{mg} \mathrm{l}^{-1}\right)$ & $x^{\prime}=\ln (x+1)$ & 4 & 3 & 20 & 6 & 3 & 6 & 4 & 1 & 22 & 4 & 3 & 7 \\
\hline Ammonium $\left(\mathrm{mg} \mathrm{l}^{-1}\right)$ & - & 0.1 & 0 & 0.88 & 0.09 & 0 & 0.71 & 0.3 & 0.01 & 39.7 & 0.135 & 0.02 & 99.9 \\
\hline Calcium (mg l$\left.{ }^{-1}\right)$ & $x^{\prime}=\ln (x+1)$ & 391 & 200 & 600 & 399 & 200 & 600 & 388 & 200 & 600 & 341.5 & 200 & 600 \\
\hline Phosphorus $\left(\mu \mathrm{g}^{-1}\right)$ & - & 200 & 0.61 & 200 & 165 & 0 & 200 & 200 & 95 & 200 & 140.5 & 0 & 200 \\
\hline
\end{tabular}


Appendix V. Fish species, their codes and the number of individuals collected in each running water type. HL, highland; LL, lowland; S, stream; R, river. Status indicates native (N) or non-native $(\mathrm{NN})$ species.

\begin{tabular}{|c|c|c|c|c|c|c|}
\hline Species name & Code & LLR & HLR & LLS & HLS & Status \\
\hline Abramis brama & abrbra & 33 & 6 & 1 & & $\mathrm{~N}$ \\
\hline Alburnoides bipunctatus & albbip & 28 & 918 & 2 & 147 & $\mathrm{~N}$ \\
\hline Alburnus alburnus & albalb & 1687 & 568 & 316 & 157 & $\mathrm{~N}$ \\
\hline Aspius aspius & aspasp & 6 & 6 & 11 & & $\mathrm{~N}$ \\
\hline Barbatula barbatula & ortbar & & 73 & 26 & 385 & $\mathrm{~N}$ \\
\hline Barbus barbus & barbar & 123 & 895 & & 72 & $\mathrm{~N}$ \\
\hline Barbus charpaticus & barpel & & 38 & & 71 & $\mathrm{~N}$ \\
\hline Blicca bjoerkna & blibjo & 297 & & 19 & 1 & $\mathrm{~N}$ \\
\hline Carassius gibelio & cargib & 89 & & 213 & 41 & $\mathrm{NN}$ \\
\hline Chondrostoma nasus & chonas & 71 & 166 & & & $\mathrm{~N}$ \\
\hline Cobitis elongatoides & cobelo & 80 & 22 & 192 & 63 & $\mathrm{~N}$ \\
\hline Esox lucius & esoluc & 96 & 15 & 29 & 24 & $\mathrm{~N}$ \\
\hline Gobio obtusirostris & gobgob & 11 & 195 & 40 & 461 & $\mathrm{~N}$ \\
\hline Lepomis gibbosus & lepgib & 10 & 8 & 27 & 9 & $\mathrm{NN}$ \\
\hline Leucaspius delineatus & leudel & & & 62 & & $\mathrm{~N}$ \\
\hline Leuciscus idus & leuidu & 139 & & 50 & 57 & $\mathrm{~N}$ \\
\hline Leuciscus leuciscus & leuleu & 6 & 46 & 6 & 69 & $\mathrm{~N}$ \\
\hline Misgurnus fossilis & misfos & 3 & & 29 & 1 & $\mathrm{~N}$ \\
\hline Neogobius fluviatilis & neoflu & 39 & 4 & 1 & 9 & $\mathrm{NN}$ \\
\hline Perca fluviatilis & perflu & 60 & 44 & 34 & 103 & $\mathrm{~N}$ \\
\hline Phoxinus phoxinus & phopho & & 28 & & 235 & $\mathrm{~N}$ \\
\hline Proterorhinus semilunaris & prosem & 51 & 2 & 41 & 1 & $\mathrm{NN}$ \\
\hline Pseudorasbora parva & psepar & 7 & 2 & 47 & 3 & $\mathrm{NN}$ \\
\hline Rhodeus sericeus & rhoser & 328 & 245 & 707 & 904 & $\mathrm{~N}$ \\
\hline Romanogobio kessleri & romkes & & 100 & & & $\mathrm{~N}$ \\
\hline Romanogobio vladykovi & romalb & 105 & 187 & 8 & 1 & $\mathrm{~N}$ \\
\hline Rutilus rutilus & rutrut & 715 & 253 & 537 & 237 & $\mathrm{~N}$ \\
\hline Sabanejewia aurata & sabaur & 7 & 48 & & & $\mathrm{~N}$ \\
\hline Sander lucioperca & sanluc & 13 & 1 & 4 & & $\mathrm{~N}$ \\
\hline Scardinius erythrophthalmus & scaery & 45 & & 225 & 10 & $\mathrm{~N}$ \\
\hline Squalius cephalus & squcep & 294 & 687 & 146 & 873 & $\mathrm{~N}$ \\
\hline Umbra krameri & umbkra & & & 19 & & $\mathrm{~N}$ \\
\hline Vimba vimba & vimvim & 3 & 94 & & & $\mathrm{~N}$ \\
\hline Zingel streber & zinstr & 1 & 22 & & & $\mathrm{~N}$ \\
\hline
\end{tabular}




\section{Captions to figures.}

Fig. 1. A diagrammatic representation of how "elements of metacommunity structure" (EMS) can differentiate among six idealized patterns of metacommunity structure and their Quasistructures, adapted from Willig et al. (2011), and originally conceptualized in Leibold \& Mikkelson (2002) and Presley et al. (2010). Note that the dark grey ovals are the EMS and the light grey area highlights the "Quasi-"structures. Quasi-structures indicate less characteristic presence/absence patterns in species distributions, and may arise due to weaker structuring mechanisms than in metacommunities where turnover is significant.

Fig. 2 Schematic representation of the study design to show how the best fit structure of fish metacommunities were examined in a hierarchical manner first at the riverscape level (all habitat types and sites are pooled), second at the level of landscape (HL, LL) types, and third, at the lowest hierarchical level, in individual habitat types (HLS, LLS, HLR, LLR). Sample abbreviations are as follows. HL, highland; LL, lowland; S, stream; R, river.

Fig. 3. Distribution of samples in the study area in the Pannon ecoregion, Central Europe, Hungary. Sample abbreviations are as follows. HL, highland; LL, lowland; S, stream; R, river.

Fig. 4. Redundancy analysis diagram showing (a) the relationship between environmental variables and the sampling sites in different stream types, and (b) the relationship between environmental variables and species composition. HL, highland; LL, lowland; S, stream; R, river. Numbers in parentheses show the explained portion of the total community variation by the canonical axes. Fish code abbreviations are as follows (see also Appendix V). abrbra: Abramis brama; albbip: Alburnoides bipunctatus; albalb: Alburnus alburnus; aspasp: Aspius aspius; ortbar: Barbatula barbatula; barpel: Barbus charpaticus; blibjo: Blicca bjoerkna; cargib: Carassius gibelio; chonas: Chondrostoma nasus; cobelo: Cobitis elongatoides; esoluc: Esox lucius; gobgob: Gobio obtusirostris; lepgib: Lepomis gibbosus; leudel: Leucaspius 
delineatus; leuidu: Leuciscus idus; leuleu: Leuciscus leuciscus; misfos: Misgurnus fossilis; neoflu: Neogobius fluviatilis; perflu: Perca fluviatilis; phopho: Phoxinus phoxinus; prosem: Proterorhinus semilunaris; psepar: Pseudorasbora parva; Rhoser: Rhodeus sericeus; romkes: Romanogobio kessleri; romalb: Romanogobio albipinnatus; rutrut: Rutilus rutilus; Sabaur: Sabanejewia aurata; sanluc: Sander lucioperca; scaery: Scardinius erythrophthalmus; squcep: Squalius cephalus; umbkra: Umbra krameri; vimvim: Vimba vimba; zinstr: Zingel streber.

\section{Captions to Appendix figures.}

Appendix I. Distance decay relationships at the riverscape level for presence/absence (Jaccard) and relative abundance (Bray-Curtis) data.

Appendix II. Distance decay relationships in highland and lowland landscape types for presence/absence (Jaccard) and relative abundance (Bray-Curtis) data.

Appendix III. Distance decay relationships at the lowest hierarchical habitat type level when all habitat types were analysed separately, for presence/absence (Jaccard) and relative abundance (Bray-Curtis) data. Sample abbreviations are as follows. HL, highland; LL, lowland; S, stream; R., 


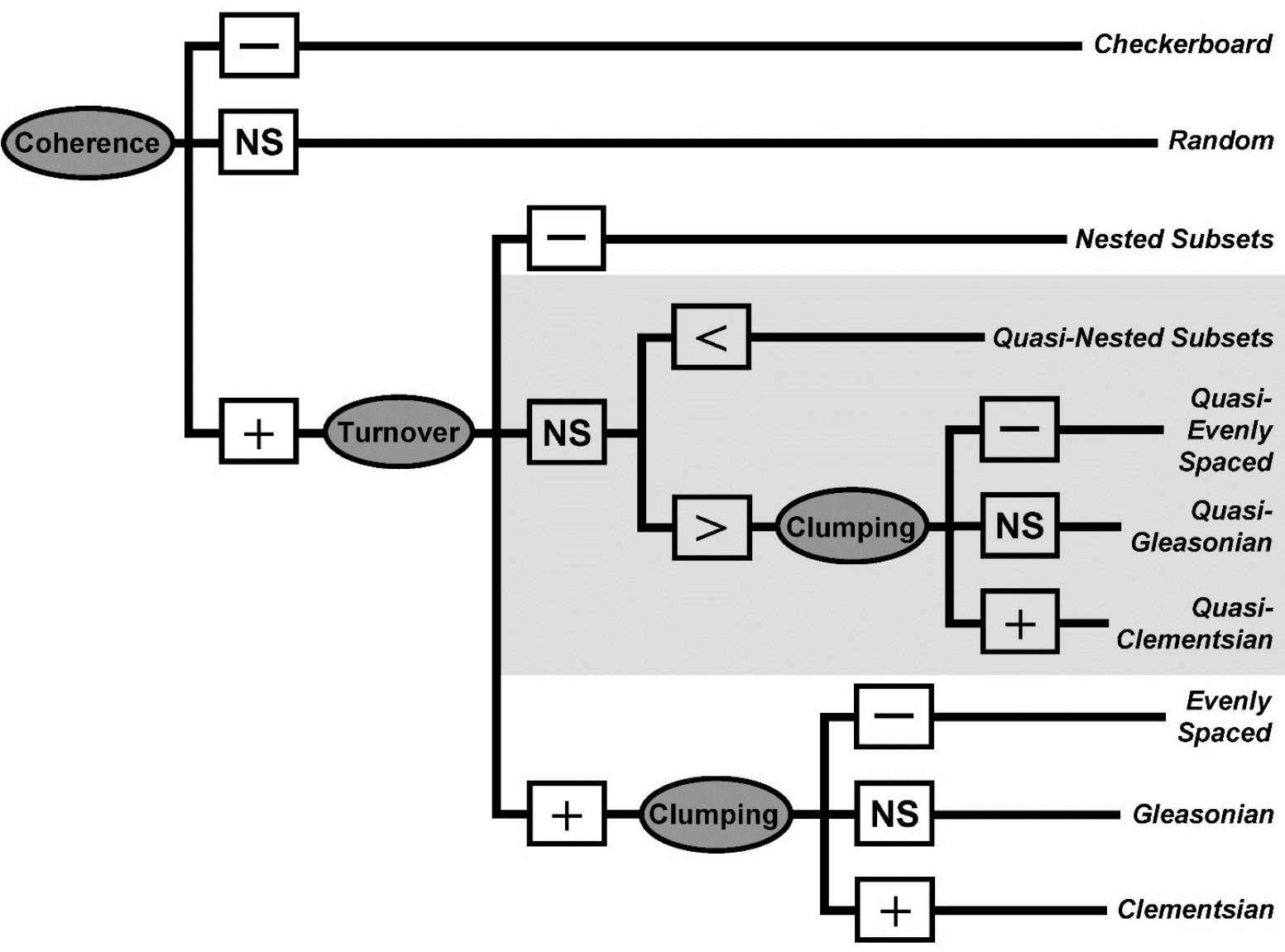


Fig. 2.

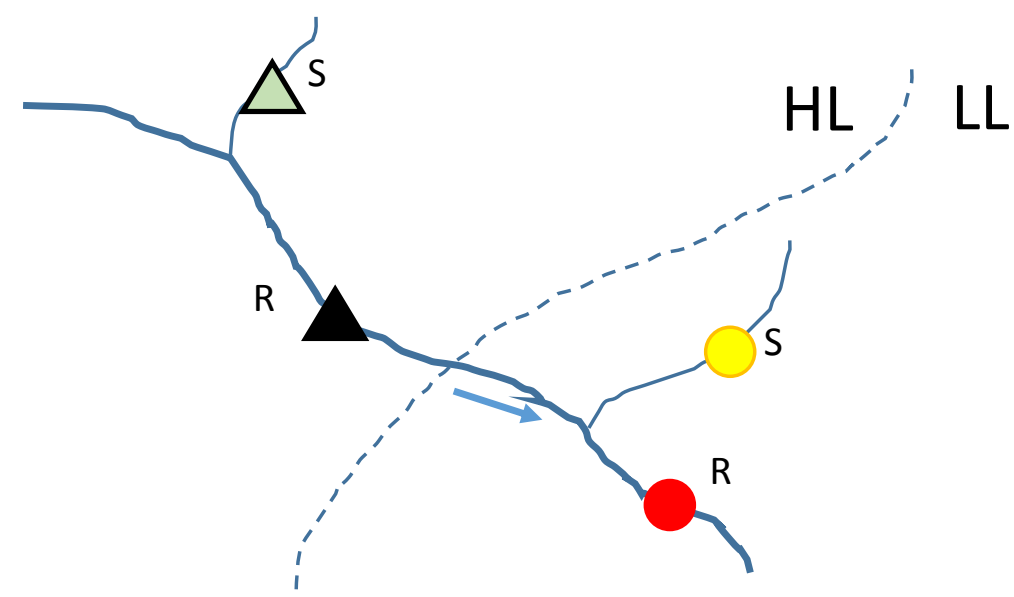

Riverscape

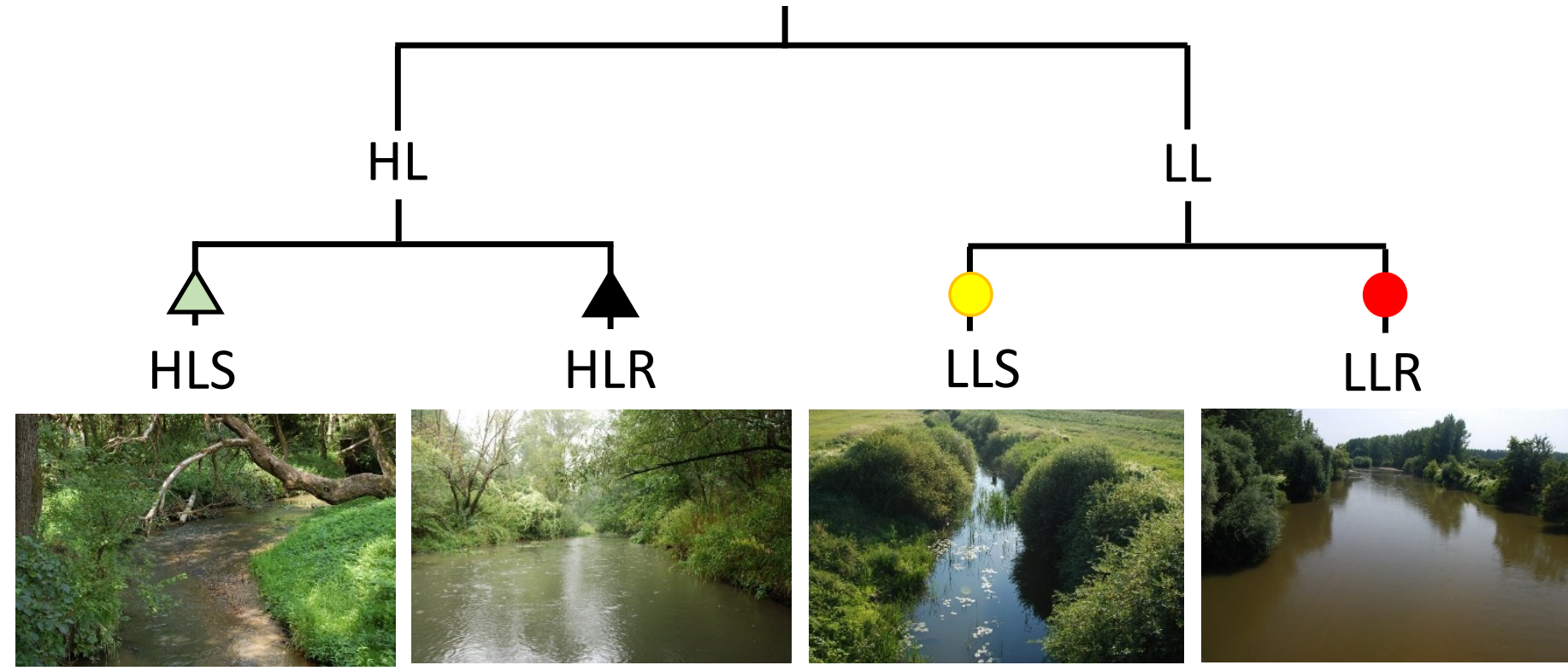


Fig. 3

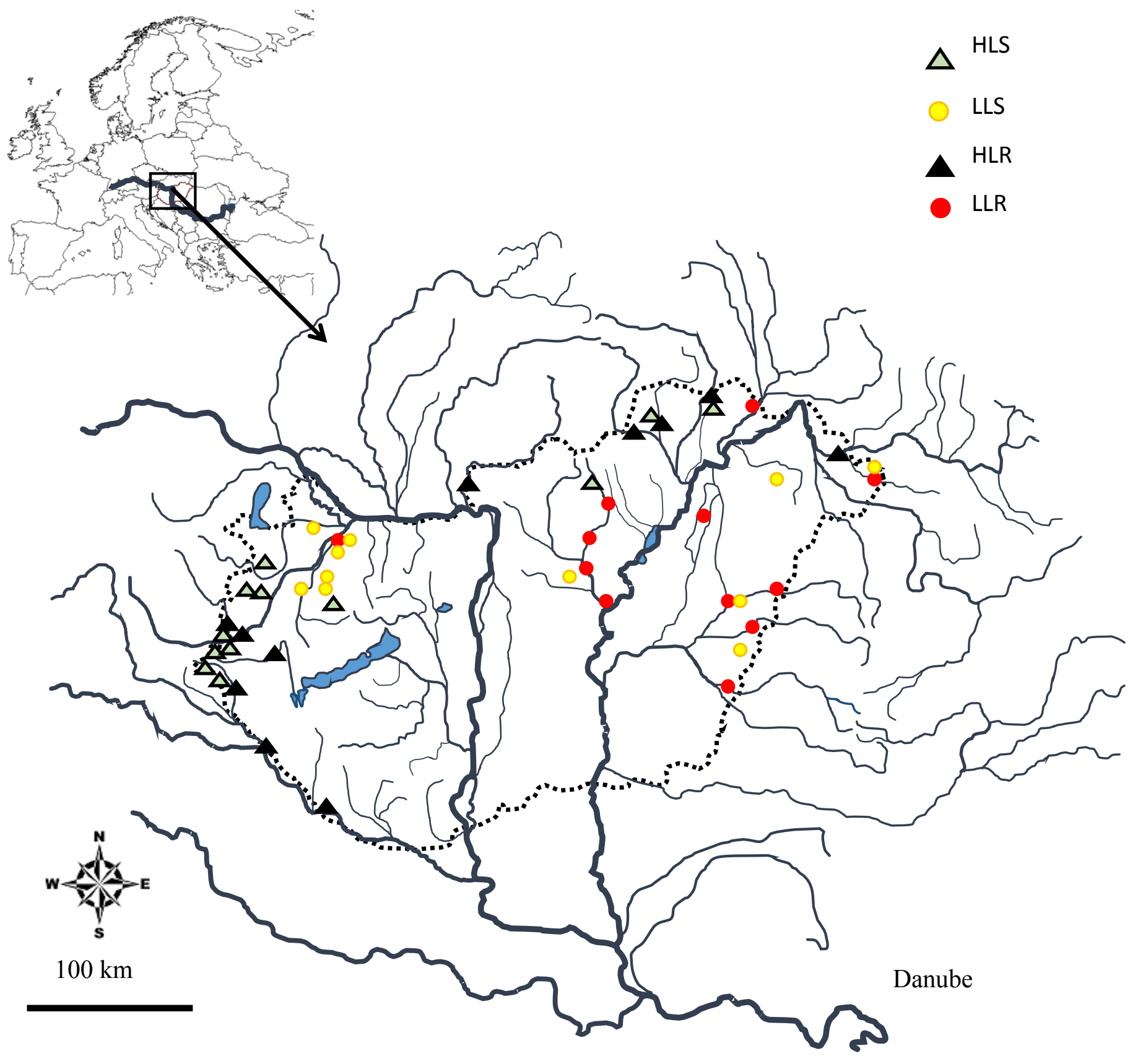


Fig. 4.

(a)

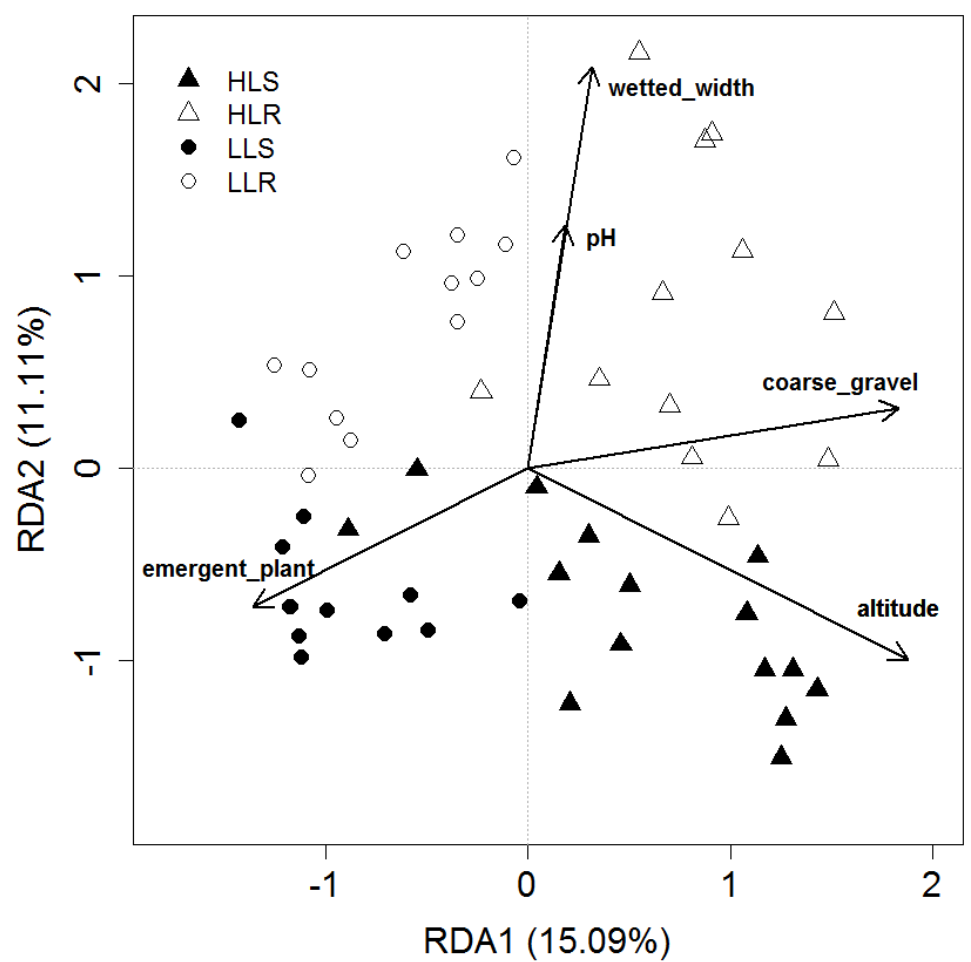

(b)

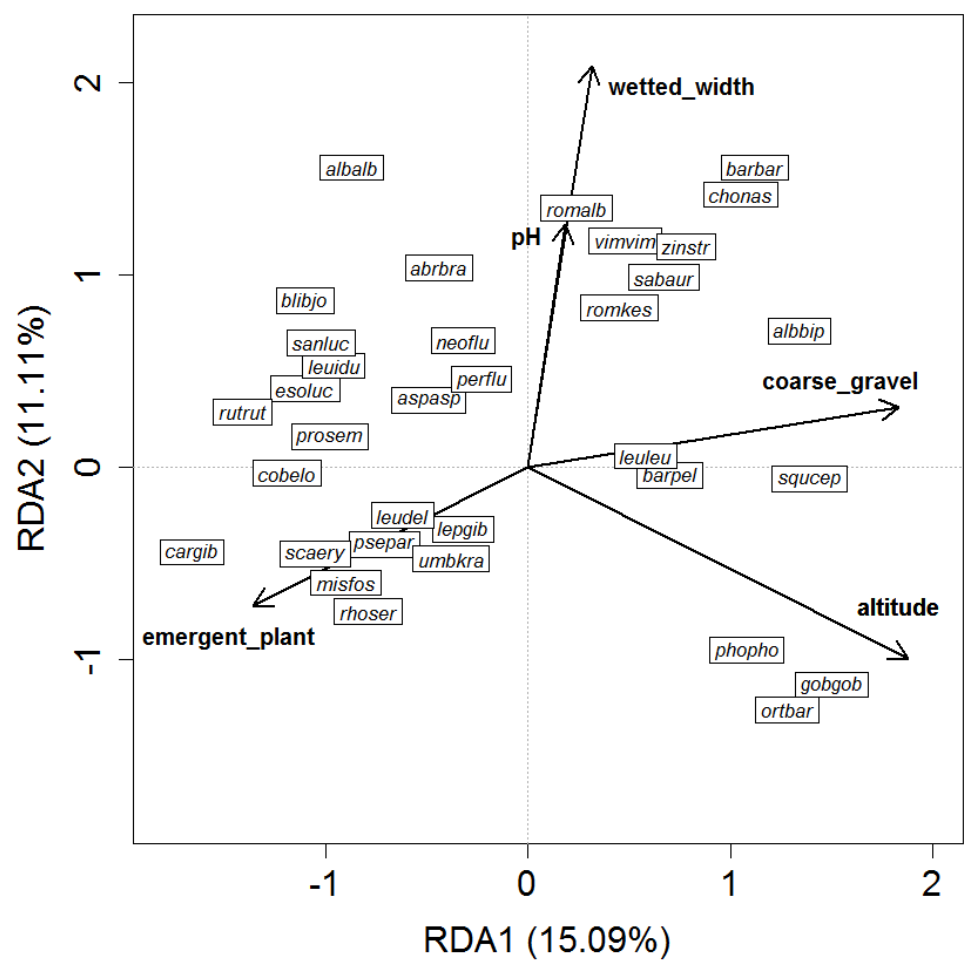

